\title{
ЦЕЛОСТНОЕ, СИСТЕМНОЕ \\ И ПСИХОТЕХНИЧЕСКОЕ ПОНИМАНИЕ ПСИХОЛОГИИ (ПРОЕКТ НОВОЙ \\ ИНТЕГРАТИВНОЙ ПСИХОЛОГИИ И СТРУКТУРЫ ПСИХОЛОГИЧЕСКОГО ОБРАЗОВАНИЯ)
}

\begin{abstract}
Аннотация. В статье ставится задача целостного понимания современной психологии в контексте истории психологии и истории культуры, а также приводятся основания для такого методологического подхода к психологии. Показываются возможности анализа психологических знаний в контексте единства культуры и ее развития. Предлагаются уровни культурно-исторического (культурологического, сочиологического), методологического и психотехнического анализа исторических и современных психологий. На основе системного анализа психологий показываются возможности конфигурирования различных психологий, возможности построения новых связей между психологической наукой и психологической практикой, а также значение такого методологического подхода $\kappa$ психологии для построения новых, более эффективных систем психологического образования.
\end{abstract}

Ключевые слова: психология, психотехника, целостность, психотехнический анализ, первичная психотехника, вторичная психотехника, психотехническая система, культурология, социология, методология.

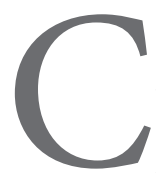

остояние современной психологии характеризуется широким многообразием концепций и подходов, слабой связанностью экспериментальной психологии и разнообразных психологических практик, но самое главное, достаточно слабой рефлексией структуры и культурно-исторической природы психологического знания и его развития ${ }^{1}$. Современная психология быстро развивается в самых разнообразных направлениях и очень трудно поддается осознанию во всей ее целокупности, остаются непонятными мотивы и механизмы ее развития. И тем более все эти трудности относятся к культурно-историческому пониманию современной психологии во всей ее целостности. Аналогичные проблемы существуют и в истории психологии, в особенности в том случае, если мы пытаемся понять современную психологию в контексте всей истории психологии. Все это создает огромные трудности в преподавании психологии и резко снижает

1 Василюк Ф.Е. Методологический анализ в психологии. М.: МГППУ; Смысл, 2003; Розин В.М. Психологическая помощь. Психотехника. Эзотерический опыт: учебное пособие. М.: Изд. РОУ, 1995; Розин В.М. Психология и культурное развитие человека: учеб. пособие. М.: Изд. Российского открытого ун-та, 1994 и др. качество психологического образования. В этой связи возникает задача целостного и культурно-исторического понимания как современной психологии, так и истории психологии.

Как же возможно такое системное понимание психологии? Прежде всего, психологию нужно узнать, познать в концептуальном плане. На первом уровне это не очень трудно. Ведь вся психология представлена в текстах, в виде моделей психики, схем психотехнического действия, в материалах психологических концепций, практик и т. п. Но в этих семиотических конструкциях психология европейского человека отчуждена и объективирована. Она, например, спроецирована на животных, на ребенка, на групповую динамику, в абстрактные концепции, тематические предметизации и т.п. Поэтому настоящая психология должна быть еще реконструирована из этого материала. Но даже теоретический анализ всего этого материала может дать определенные закономерности развития европейской психологии и некоторые общие представления о ее структуре. И мы обнаружим, что вся совокупность существующих психологий - это не просто некоторый конгломерат представлений, но в нем просматривается определенное развивающееся и осмысленное целое. 


\section{Психология и психотехника $7(58) \cdot 2013$}

Став на путь такого понимания психологии и реализовав его, мы можем затем, в самом начале представить психологию как осмысленное целое, вместе с целью этого целого и смыслом этого развивающегося явления культуры. И мы можем прямо сказать студенту: «Вот она и есть ... психология». То есть мы можем с самого начала задать полную ориентировочную основу психологии, полную ориентировочную основу деятельности для понимания всей психологии, психологии в ее целом, следуя которой студенту гарантируется $u c$ черпывающее и полное понимание психологии. Правда, для этого нужно проделать определенную работу, но она будет осмыслена и целенаправленна. На следующих этапах будет происходить только углубление этой ориентировки и уточнение ее, развертывание и реализация ее в материале, ее рефлексивная и феноменологическая раскрутка. Но целое и содержательно, и методически дано с самого начала. Тогда появляется новый смысл и новая методология психологического образования. Конечно, для этого мы сами должны знать психологию.

Таким образом, мы ставим задачу познания психологии в целом, всей психологии. Для последующего методологического анализа эта совокупность психологий разного уровня является только материалом. И поскольку психология предположительно представляет собой нечто единое целое, то ее важно знать и в первом приближении понимать именно целиком. Ухватить эту эмпирическую и неоднородную целостность на всех уровнях существования психологии как раз и важно на первом шаге анализа.

Затем эту неоднородную целостность психологий необходимо воспринять и рефлектировать на следующем уровне анализа, который можно назвать методологическим. Здесь мы должны, прежде всего, логико-методологически идентифицировать основные направления психологии (как научной, так и практической), соотнести их друг с другом, исследовать основные теоретико-методологические оппозиции современной психологии и реконструировать те познавательные и практико-методические задачи, которые различные психологии и психологические подходы решают. Здесь также важно изучить развитие этих аппозиций в истории культуры и истории психологии и обнаружить основные их культурно-исторические коннотации.

Рефлексивный анализ психологии может позволить здесь реконструировать основные структуры психологического знания и познания. Знание же здесь должно браться всегда в отношении к методам его получения. Таким образом, мы обнаружим в разных психологиях различные типы знания, разные методы познания (влияния и т. п.) и различные типы опыта, которые в каждом случае являются предметами и средствами организации познания. Вследствие такого анализа может быть сформирована целостная картина функционирования и развития психологического знания в культуре, которое теперь предстанет рефлексивно и методологически обработанным. В конечном счете, здесь мы можем установить все связи между психологическими концепциями и теми психотехническими реальностями культурно-исторического опыта, которые каждая из них рефлектирует.

Для методологического анализа различные психологии, психологические концепции, практики и вся реальная психология, которая включена в культуру это лишь материал. И от полноты представленности данного материала здесь будет зависеть качество и глубина методологического анализа. Таким образом, поскольку мы ориентируемся на целостное понимание психологии, хотим увидеть в ней некоторое развивающееся целое, то его, это целое, необходимо знать и в первом приближении понимать именно целиком уже на уровне анализа материала.

Но какие мы имеем методологические основания для постановки задачи видения психологии как целого, ведь, казалось бы, она представляет собой лишь отдельные направления, разные предметные области и т.п.? Здесь можно отметить следующее. Ведь психологию, психологические теории, психологические практики производят люди, которые являются носителями нашей культуры, той культуры в широком смысле, в которой мы живем. И они производят психологию изнутри различных культурно-исторических ситуаций, которые создает, например, западная культура в процессе своего развития. В этом смысле, психология или совокупность всех психологий представляют собой некоторое более или менее целостное представление, например, западной культуры о себе самой, пусть и по-разному и в разных аспектах, а также о человеке и социальных группах в этой культуре. Во всяком случае, все психологии исходят из этого целого культуры, осознают и рефлектируют именно его, а поэтому в них эта целостность культуры определенным образом отображается.

Это, так сказать, горизонтальный срез целостности психологии. Но существует еще и вертикальное измерение целостности психологии. Ведь психология - это и та реальность, в которой мы живем и которая живет внутри нас, реальность, которой мы следуем, в которую верим и которая нас, в сущности, производит (психотехническая реальность). Такие психотехнические реальности являются, в свою очередь, основой для психологических концепций и практик, которые собственно их и рефлектируют. В этом отношении, 
та целостность психологии, с которой мы имеем дело, неоднородна и в вертикальном измерении. Здесь, с одной стороны, мы имеем дело с непосредственными, жизненными психологическими (психотехническими) реальностями, а с другой стороны, с разными уровнями их психологической рефлексии. И тут также требуется соответствующий методологический подход к реконструкции всевозможных рефлексивных процедур, которые используют различные психологии. Наконец, необходим методологический анализ психологий с точки зрения их исторического развития.

$$
* * *
$$

Но одного методологического анализа недостаточно. Ведь все рефлексивные психологии, в конечном счете, опираются на более непосредственные психотехнические реальности, на различные «жизненные психологии» (М.М. Бахтин), они вырастают внутри определенных культурно-исторических ситуаций, в которых западная культура открывает себя с разных сторон $^{2}$. А это значит, что методологический анализ психологий необходимо углубить. Поэтому на следующем шаге анализа, удерживая эти психологии внутри целого в синхронической и диахронической плоскостях, нужно погрузить их в историю, дать им историческую жизнь. Здесь важно посмотреть на это психологическое целое и его части культурологически и социологически. Соответственно, необходим культурологический и социологический анализ всей этой психологии. Например, по отношению к каждому направлению психологии важно применить анализ с точки зрения социологии знания, с точки зрения типа опыта, который рефлектирует данная психология и т.п. Такой анализ позволяет получить из материала психологии психотехники, лежащие в ее основе, социальные и культурные условия возможности данной психологии, самосознание, на которое она ориентирована, условия ее производства в культуре и т.п. Таким образом, мы получим многогранно рефлектированную психологию ${ }^{3}$.

Здесь мы приходим к пониманию важнейших причин существования различных психологий. Они состоят, в том числе, и в различии задач, которые разные психологии сознательно или бессознательно перед собой ставят. Понятно, что психология, которая ставит задачу спасения души, и психология, ориентированная на манипуляцию массовым сознанием, - это разные

2 Волошинов В.Н. (Бахтин М.М.) Марксизм и философия языка: Основные проблемы социологического метода в науке о языке. М.: Лабиринт, 1993; Бахтин М.М. Эстетика словесного творчества. М., 1979.

3 Олешкевич В.И. История психотехники. М.: Академия, 2002. психологии и у них будут различные представления о психике. И это их различие определяется, прежде всего, их целями и ценностями. Так мы можем осознать и рефлектировать истоки, ценности и цели бихевиоральной, современной когнитивной психологии, различных направлений глубинной психологии и т. п. Например, мы можем понять, что психологии 3. Фрейда, А. Адлера, К.Г. Юнга, К. Роджерса отличаются культурно-историческим опытом, который они рефлектируют, а также своими целями психотерапии и ценностями человеческой жизни, которые одновременно характерны для западной культуры ${ }^{4}$.

Но ценности психологий, особенно психологий $\mathrm{XX}$ в., важно понимать экзистенциально-динамически. Это не обычные рассудочные ценности, которые наполняют нашу жизнь и не рефлексивные философские ценности. Они вырастают из фундаментальных проблемно-экзистенциальных ситуаций в культуре, вызревают из самых глубин западной культуры и сами несут в себе новую культуру. Эти ценности несут в себе экзистенциальные ориентиры индивида в новых культурно-исторических ситуациях и являются жизненно значимыми прежде всего для определенных социальных групп. Но такие ценности могут быть различны и даже противоречить друг другу.

Наиболее отчетливо данную ситуацию в психологии осознал К. Г. Юнг. Он говорил, что если бы он последовал фрейдовской психологии, то стал бы невротиком, потому, что это не его психология, она не соответствует его жизненному опыту и его жизненным проблемам. Но одновременно он признавал и значение психотерапии 3. Фрейда и А. Адлера для соответствующих групп пациентов ${ }^{5}$. Но и для Фрейда, и для Адлера их психологии основывались на их собственном проблемном опыте, они и жили согласно своим психологиям. И их жизнь превратилась в настоящий психологический эксперимент по осознанию нового опыта в культуре, по его рефлексии и социальному его испытанию. Так что три этих направления психологии представляют собой три способа выхода из тех затруднений, в которые попала европейская культура, и они несут в себе три типа ценностей, ценностей не только психотерапии, но и человека, и человеческой жизни. Эта ситуация в психологии говорит не только о неоднородности западной культуры, но и о различных направлениях ее развития.

\footnotetext{
4 Олешкевич В.И. История и логика развития европейской психотехники. М.: МОСУ, 2005; Олешкевич В.И. Психология и психотерапия А. Адлера. М., 2010; Юнг К.Г. Тэвистокские лекции. Аналитическая психология: ее теория и практика. Киев: СИЕНТО, 1995.

5 Юнг К.Г. Тэвистокские лекции. Аналитическая психология: ее теория и практика. Киев: СИЕНТО, 1995.
} 


\section{Психология и психотехника $7(58) \cdot 2013$}

Эта неоднородность западной культуры должна стать самостоятельным предметом культурно-исторического анализа, поскольку развитие психологий происходит и на стыке различных предметностей культуры, а также в ситуации систематической коммуникации между различными психологиями, опирающимися на собственный культурно-исторический опыт и различные формы его психологической рефлексии. Такая коммуникация происходит и в диахроническом разрезе западной культуры, и в межкультурном пространстве. Вместе с тем, современная западная культура систематически регрессирует и извлекает более глубокие пласты своего опыта, а также находится в состоянии межкультурной коммуникации и инкорпорирует в себя иные формы опыта и, казалось бы, инородные ей психологии. Так, например, восточная психология сегодня включена в общий контекст развития западной психологии. С одной стороны, она противостоит западной психологии, но, с другой стороны, она находится в активном диалоге с нею и оказывает непосредственное влияние на формирование западной психологии. Во всяком случае, элементы восточной психологии включены во многие направления и виды западной психотерапии, часто без какой-либо специальной рефлексии этого процесса межкультурного диалога.

Но если мы подходим к психологии культурологически, то нужно принимать все цели и ценности, которые являются укорененными в культуре. Мы должны предположить, что культура есть некоторое развивающееся целое. И, таким образом, целостность современной психологии ассоциируется с целостностью культуры. На основе такого анализа мы начинаем понимать, откуда «растут ноги» у новых психологий. Тематически и структурно разбросанная, экзистенциально расчлененная и рассеянная сеть рефлексивных психологий всегда определенным образом отображает состояние общественного сознания. Она является также средством его самоорганизации, воспроизводства и развития. Но все же эти психологии все вместе отображают некоторое единство культуры и европейского сознания, пусть и рассеянное. И это единство определенным образом сохраняется даже в каждой частной психологии. Например, многообразие психологий можно разбить на два класса на основе психотехнической оппозиции «самоосознание/формирование». Но, вместе с тем, во всякой психологии мы всегда можем найти также и второй элемент этой оппозиции (например, в психоанализе существует и подкрепление). Так что всякая, более или менее разработанная психология является в некотором роде и микрокосмосом всей психологии, монадой, содержащей в себе все целое.
Культурно-исторический опыт, который рефлектируют психологии формируется обществом и культурой, в которой эти психологии возникают. Следовательно, для их понимания мы должны осуществить анализ культурологии и социологии этого опыта, а также реконструировать его психотехническую структуру. Ведь именно этот опыт или его определенную ипостась осознают и рефлектируют различные психологии. Затем мы можем сравнить данные этого анализа и тот ракурс или характер понимания и уровень рефлексии, которые используют различные психологии в своей концептуализации этого опыта.

В таком случае мы обнаружим не только специфику психологической рефлексии культурно-исторического опыта, но и зоны опыта, которые по каким-то причинам остались нерефлектированными, например, потому что не нашлось средств для такой рефлексии. Исследуя внутреннюю динамику опыта культуры, мы можем также и прогнозировать возникновение новых психологий в ближайшем будущем. Но самое главное то, что здесь мы можем понять некоторую культурноисторическую «анатомию» и «физиологию» различных психологий.

Но и сами психологии, психологические школы и направления отнюдь не являются бестелесными субъектами, они тоже имеют свои социальные интересы, ценности и имплицитные основания. Они обычно формируются как реакции социальной эмансипации в кризисных ситуациях культуры. А это означает, что для их понимания необходим социологический и культурологический анализ также соответствующих психологических теорий и практик. Новые психологии развиваются в обществе как живые социальные организмы по некоторым социальным законам. Они вступают в борьбу друг с другом, развиваются в тесном концептуальном диалоге и т. п. И социальный выигрыш здесь зависит не только от концептуальной адекватности психологии, но и от ее социальной организации, социальной активности, концептуальной лабильности и т.п. Например, психоанализ Фрейда был, в сущности, отнюдь не глубже психологии Юнга, Адлера или Р. Штайнера, но он оказался более организован и, по стечению ряда культурно-исторических обстоятельств, более востребован определенной социальной группой западного общества. Всякая новая психология в действительности является идеологией определенной социальной группы, с ее потребностями, проблемами и подходящими для ее представителей способами 
решения жизненных проблем ${ }^{6}$. Так что всякая школа в психологии требует своего соответствующего социологического анализа7.

Осуществив такой развернутый анализ, мы можем получить некоторую экзистенциальную топологию культуры, фиксирующую определенные проблемные точки ее экзистенциального самосознания, типичные проблемные ситуации, способы их обозначения и рефлексии, а также формы их коррекции и направления развития. В этом пространстве культурного опыта мы можем увидеть различные типы разрывов сознания в культуре, различные формы проблемных ситуаций и их специфическую культурологическую и социологическую структуру (социальную конструкцию), а также их различные уровни или социокультурные страты, инициирующие специфику психологического самосознания индивида в таких ситуациях и способы психологической рефлексии.

Исследуя таким образом ситуацию, внутри которой рождается новая психология, мы можем понять ее культурно-историческую конституцию и базовую психотехническую структуру. Только таким образом мы можем по настоящему понять психологию бихевиоризма, Л.С. Выготского, 3. Фрейда, А. Адлера, К.Г. Юнга, К. Роджерса и др. Так мы можем составить специфическую экзистенциальную и культурно-историческую карту современных психологий, которая станет важным средством целостного и системного понимания как современных психологий, так и психологий близкого и дальнего прошлого ${ }^{8}$. Все это позволяет увидеть психологию как единое культурно-историческое целое в синхроническом и диахроническом модусах ее рассмотрения.

Это культурно-исторически рефлектированное целое, в которое помещены все психологии, задает культурологическую основу для понимания каждой отдельной психологии, которая теперь осмыслена именно внутри целого, обосновывающего ее изнутри более широкого и глубокого пространства культурноисторического опыта. В таком случае, психология из теории психики или вида психотерапии превращается в глубинную экзистенциальную реакцию культуры или в реплику самосознания определенной социальной группы в кризисной ситуации культуры. Таким обра-

\footnotetext{
6 Адлер А. Наука жить. К.: Port-Royal, 1997; Фрейд 3. Введение в психоанализ: Лекции. М.: Наука, 1989; Штайнер Р. Очерк теории Гетевского мировоззрения. М.: Парсифаль, 1993.

7 Олешкевич В.И. Психология и психотерапия А. Адлера. M., 2010.

8 Олешкевич В.И. История психотехники. М.: Академия, 2002.
}

зом, это целое культурно-исторического опыта задает некоторую рамку для понимания каждой отдельной психологии. Здесь наше понимание идет от целого к его частям. Но и культурно-исторический анализ отдельной психологии тоже приводит нас в рамки этого целого, а также уточняет и детализирует его. В этом состоит специфический герменевтический круг, к которому мы приходим, ставя вопрос о целостном и культурноисторическом понимании психологии.

Наконец, необходимо перейти на уровень собственно психотехнического анализа. Что же мы можем получить в результате такого исследования? Обычно психологические проблемы формулируются исключительно онтологически: что такое личность, сознание, психика, мышление и т.п. И такой подход действительно характерен для науки. Но психология отличается от естественных наук тем, что ее предмет историчен, он меняется вместе с ходом истории. Психика, которая нам дана как проблема и как предмет исследования, является культурно-историческим явлением. Если мы внимательно посмотрим на историю психологических концепций, то увидим, что они описывают именно современную им историческую психику, но с точки зрения определенной экзистенциально-исторической ситуации. То же можно сказать и о современных психологиях.

Психологии возникают для понимания и объяснения определенных проблемных ситуаций в культуре. Они разные потому, что различны порождающие их проблемные ситуации в культуре. Но каждая психология несет соответствующее ее месту и функции в истории понимание человека и, в этом смысле, каждая психология имеет свою истину. Так обстоит дело, когда мы стремимся понять каждую психологию исторически. В этом случае, изучая определенную психологию, мы можем нечто понять о той культурно-исторической ситуации, изнутри которой она говорит, так же мы можем нечто уяснить в отношении той психики, которую она изучает. Это можно показать на материале бихевиоризма, психоанализа, гуманистической, советской психологии и других направлений психологии.

Другими словами, новые психологии возникают не на пустом месте. Они возникают внутри проблемных ситуаций в культуре, в ситуациях разрывов самосознания людей, в ситуациях потери понимания и переживания внутренних конфликтов, которые уже нельзя разрешить старыми средствами. Если мы принимаем это положение, то должны рассматривать всю совокупность современных психологических концепций как определенное психотехническое 


\section{Психология и психотехника 7(58) • 2013}

поле осознания современных проблемных ситуаций человека в культуре и попыток их разрешения. Опираясь на такую исследовательскую точку зрения, мы можем редуцировать современные психологические концепции к тем базовым проблемным ситуациям, внутри которых они стали возможны и которые их конституируют. Это и будет более глубоким пониманием этих психологий.

Но появляющаяся в истории совокупность проблемных ситуаций всегда связана с определенными, уже принятыми в культуре постулатами, которые задают для индивида образ жизни, ориентиры развития, цели жизни (например, спасения, достижение материального благополучия, социальной состоятельности и т.п.). Другими словами, новые психологические проблемы возникают на основе некоторой, уже ранее существовавшей в культуре матрицы постулатов, идентификаций, правил, побуждений, запретов, санкций и т.п. Эта матрица, в сущности, образует определенную психотехническую систему развития самосознания индивида и воспроизводства им определенного психосоциального опыта. Она может выстраиваться в целостную психотехническую культуру. И новые психологические проблемы возникают в том случае, когда старые психотехнические механизмы их разрешения уже не работают, не срабатывают или оказываются непродуктивными в новой ситуации. Именно так можно понять возникновение новых психологий в ХХ в. ${ }^{9}$

Когда старая психотехническая система не срабатывает, возникают новые типы проблем, а вместе с ними новое поле психологического проблемного опыта. На этом поле и возникают новые психологии. Конкретные проблемные ситуации в этом поле являются специфическими источниками разработки определенных психологий. Исследуя это поле психологических проблем, мы можем построить некоторую психологическую топологию проблемно-экзистенциальных ситуаций определенного культурно-исторического поля психотехнического опыта.

Такого рода поле психологических проблем и их топология зададут определенную совокупность проблемных ситуаций в культуре в определенное время (в синхроническом разрезе). И анализируя существующие в это время психологии (направления психологии) мы можем соотнести их с выделенной топологией проблемных ситуаций в культуре и идентифицировать развитие каждой отдельной психологии с определенной проблемной ситуацией или некоторой их структурой. В результате такой идентификации мы получаем определенные ячейки рефлексии проблемного психологиче-

\footnotetext{
9 Там же.
}

ского опыта в культуре в рамках различных психологий. Совокупность таких ячеек будет изображать некоторую исторически обусловленную психологическую и психотехническую реальность психологии определенного времени (например, современной психологии).

Такого рода описание существующих в одно и то же время психологий представляет собой, в сущности, описание двух психотехнических реальностей. С одной стороны, это старая, проблемная психотехническая реальность, с другой стороны, это осознающая и рефлектирующая эту реальность совокупность новых психологий. Это вторичная психологическая реальность. Но если мы надлежащим образом будем анализировать первичную, проблемную психотехническую реальность, то может оказаться, что не все проблемные ситуации и их связи осознаны новыми психологическими концепциями, некоторые из них могут остаться и нерефлектированными. Такие пропущенные места в проблемном поле первичной психологической реальности могут оказаться весьма важными для понимания пробелов, существующих в рефлексивных психологиях. Это также дает возможность, уже на этом уровне анализа, прогнозировать возникновение новых психологий.

Итак, новые психологии возникают на том месте культурной реальности, где старая психотехника не срабатывает или разрушена. Культурная же функция новых психологий состоит в том, чтобы по-новому разрешить проблемные ситуации, то есть новые психологии должны выполнять психотехническую функцию. Поэтому крупные направления психологии являются, прежде всего, новыми психотехниками. Они открывают новые способы управления психикой и новые методы развития индивида. Обновленные интерпретации психологических проблем и новые методы работы с ними образуют новое поле разработки открытого проблемного опыта. Что касается вопроса о том, что открывается прежде, новый предмет или новый метод, то на него следует ответить, опираясь на логику открытия. В результате систематического переживания проблемной ситуации усматривается, прежде всего, новое видение ситуации и себя в ней. Только затем это видение в результате его рациональной обработки разделяется на предмет и метод. И уже потом, в процессе дальнейшего развития психологии, они начинают активно взаимодействовать и влиять друг на друга ${ }^{10}$.

Новые психологии обозначают старую психотехническую реальность, разрабатывают свои новые обозначения и формируют соответствующие объяснительные

10 Олешкевич В.И. Психология и психотерапия А. Адлера. M., 2010. 
концепции. В ходе их разработки формируются третичные психологические проблемы. Причем в каждом психологическом направлении формируются свои соответствующие проблемные области. Это проблемы, которые теоретически опосредованы концептуализациями исходного для данной психологии круга проблем. Например, 3. Фрейд создает сексуальную интерпретацию этиологии неврозов, затем формирует концепции либидо, детского психосексуального развития. На этой теоретической основе появляются вопросы об отношениях взрослых к сексуальному поведению детей, вопросы сексуального воспитания и т.п. И на эти вопросы (созданные ею самой) психоаналитическая концепция вынуждена отвечать. На основе теоретических разработок определенного проблемного поля опыта могут развиваться также третичные психотехники, которые рефлектируют психотехнический элемент психологий и рассматривают его как самодостаточное целое, способное стать средством для решения широкого круга задач (например, НЛП). Но такие психотехники могут быть направлены также на решение уже теоретически сконструированных проблем. На этом уровне появляются также глобальные психотехнические установки (как, например, «будь аутентичен», «осознавай себя», «будь искренним, эмпатичным» и т.п.).

Таким образом, всякая психологическая концепция основывается на некотором проблемном континиуме старого психотехнического опыта. Именно над ним и надстраивается новый психотехнический пласт опыта, стремящийся разрешить возникшие в культуре проблемные ситуации. Сюда входят также новые обозначения психической реальности и их концептуальная разработка. Дальнейшая рациональная обработка этих концептуализаций образует третичное поле психологических проблем, а также психотехники третьего уровня. Эти пласты опыта можно увидеть как в развитии современной психологии в целом, так и в развитии отдельной психологической концепции.

$$
* * *
$$

Но это только объективное понимание целостности современной психологии. Для настоящего понимания психологии необходимо обернуть весь этот массив психологических знаний на себя, ибо по-настоящему я могу понять психологию только на себе и опираясь на свой личный опыт. Теперь не я погружаюсь в историю, а история в очищенном психотехническом виде начинает функционировать в моем сознании. Здесь важно всю эту психологию осознать на уровне собственного самосознания и пережить феноменологически, а также проработать психотехнически в рамках своего личного опыта. Теперь мы можем психотехнически прочувство- вать все основные грани культуры (и диалога культур), истории психологии, но также и выйти за пределы исторического опыта и посмотреть на него извне.

Это психотехническое переживание истории внутри себя, стратификации и многообразия исторического опыта, может стать личной мотивацией и задачей такого рода феноменологического исследования. Мы должны на собственном опыте осознать психотехники самосознания, влияния, формирования, подкрепления, в частности, на основе того, как было организовано наше формирование ближайшим социальным окружением, того, как влияют различные элементы общественного сознания на нас в данный момент и т.п. Теперь важно также и изнутри понять различие психологий, различие проблем, на которые они ориентируются, значение различных интерпретаций этих проблем и то, как конкретные техники опосредованы всеми этими обстоятельствами. Например, психологии 3. Фрейда, А. Адлера, К.Г. Юнга важно также изнутри понять и ценностно, как различные грани проблематизации состояния человека в первой половине $\mathrm{XX}$ в. и как имеющие разные, в том числе и терапевтические, задачи. Фрейд ставит задачу освободить индивида от груза детства и поставить бессознательное под контроль эго, Адлер же полагал, что человек не должен быть эгоистом, но ему для психического здоровья нужно быть полезным для общества, а Юнг основную ценность терапии видел в индивидуации. Но это совершенно разные, хотя и одинаково хорошо обоснованные, ценности психотерапии.

Эти ценности были обусловлены личным опытом этих психологов. Когда Юнг говорил, что если бы он стал фрейдистом, то превратился бы в невротика, то это значит, что ему для исцеления и организации собственного развития нужна была иная психология ${ }^{11}$. Адлер на каждом шаге развития своей психологии компенсирует раз за разом свои личные неполноценности $^{12}$. Таким образом, их психологии были их личным делом и также опираясь именно на свой личный опыт, мы только и можем их по настоящему понять. А понять эти психологии можно только практически, проработав их на себе. Потому что теоретически психологию по настоящему понять нельзя.

Психологию нельзя понимать (а тем более критиковать) «вообще». Каждая система психологии обусловлена определенным опытом, который она рефлектирует и задачами, которые она решает. И, исходя

11 Юнг К.Г. Тэвистокские лекции. Аналитическая психология: ее теория и практика. Киев: СИЕНТО, 1995.

12 Олешкевич В.И. Психология и психотерапия А. Адлера. M., 2010. 


\section{Психология и психотехника 7(58) • 2013}

из этой ее обусловленности, конкретную психологию и необходимо понимать. Но эти задачи не всегда лежат на поверхности и очевидны. Часто, чтобы их понять, нужно вначале реконструировать психологию. Таким образом, понимание психологии не просто рационально, не линейно и не одноуровнево. Оно требует не только аналитической, но и практической работы. Но иного пути для рефлектированного и сознательного понимания психологии, пожалуй, и нет.

$$
* * *
$$

Результаты такого анализа психологии открывают новые и широкие возможности для развития как экспериментальной психологии, так и психологической практики, которые на психотехническом уровне их анализа уже мало чем отличаются друг от друга. Они задаются в рамках одной психотехнической парадигмы, поэтому их данные принадлежат одному уровню анализа, так что экспериментальная психология и психологическая практика могут говорить на одном языке, а данные их обоих могут рефлектироваться в рамках одной психологической теории или методологии. Теперь мы понимаем, что психологическая наука, как наука в целом, всегда имплицитно технологически (технически) ориентирована и рефлексия этого факта автоматически устраняет разрыв между психологической наукой и психологической практикой.

Данный тип анализа позволяет также конфигурировать различные психологии. Когда мы обнаруживаем, что в основе всякой психологической теории лежит определенная психотехническая схема развития психики, то у нас появляется возможность психотехнически проанализировать данные этой психологии, а также найти им место в психотехнической системе организации развития психики и если необходимо, устранить существующие здесь пробелы в знаниях. Например, исследуя психотехническую схему деятельности, мы должны добавить сюда психотехнику идентификации, поскольку деятельность всегда опирается на определенную идентификацию самосознания индивида. Также мы можем дополнить и психотехнику подкрепления, разрабатывая, с одной стороны, ее технические возможности, а с другой стороны, дифференцируя различные особенности ее объектов. В таком случае подкрепляться могут не только поведенческие реакции, но и многие другие психические процессы, такие, как экстериоризация, интериоризация, проекция, интроекция, осознание и многие другие. Разрабатывая психотехнику самоосознания, мы можем совместно проанализировать все основные методы и техники глубинной психологии именно в методологической и психотехнической плоскостях, в результате чего мы получим определенные методические вариации данной психотехнической схемы в связи с разными задачами ее использования и различными условиями опыта. Обычно же такой анализ осуществляется только на теоретическом уровне. Методологический анализ позволяет соотнести теоретические знания различных психологий с их методами и задачами, а также с условиями их истинности и эффективности.

Но поскольку все психотехнические схемы, которые мы обнаруживаем в исторических психологиях являются психотехническими схемами развития психики и представляют собой культурно-исторически обоснованные срезы или аспекты некоторой целостной психотехники развития, то появляется возможность их конфигурирования в рамках целостной психотехнической системы, где каждой психотехнической схеме отводится свое особое место и своя функция. Здесь мы, например, понимаем, что существует как реактивность психики и поведения, так и их активность, что не только деятельность является условием развития психики индивида, но и самосознание и т.д. Такое конфигурирование психологических знаний собирает их в одну целостную психотехническую систему, опираясь на которую можно строить психологические теории и практики с определенными заданными свойствами и под конкретные задачи.

$$
* * *
$$

Если мы способны представить психологию в таком целостном виде, и в синхроническом, и в диахроническом пространствах ее функционирования и развития, то мы получаем возможность использовать новый, холистический подход к психологическому образованию. В таком случае перед студентом психология с самого начала предстать в своей целостности, и как современная психология, и как психология в ее историческом развитии. Это дает возможность понимать новые психологии в их соотнесении с тем историческим опытом, который они рефлектируют, а также понимать телеологичность, психотехничность и конструктивность психологического знания. Таким образом, обучение будет включать обязательным своим элементом методологическую рефлексию.

Такой подход будет включать в себя и социологическую рефлексию, фиксирующую социальные условия формирования психологического знания, и изучение социальных механизмов его формирования (социологию знания), и исследование диалогичности психологического знания, а также особенности его социальной востребованности и специфику его ориентации на потребителя. В так построенное психологическое образование может включаться и культурологическая 
рефлексия психологического знания, анализ самосознания, идентичности, на которых оно формируется и «живет», культурологический анализ ситуаций его формирования и т.п.

При таком рефлектирующем холистическом подходе к психологическому образованию психологическое знание станет рефлектированным одновременно в нескольких направлениях, и у студента будет формироваться необходимость и потребность в такой рефлексии. Таким образом, усвоенное психологическое знание будет самосознающим знанием и, следовательно, обреченным на развитие. Но одновременно оно будет оставаться исторически укорененным, культурно-исторически рефлектированным и целостным, поскольку его целостность онтологически задается с самого начала и кладется в основу психологического образования.

Но особенно важно, что при таком подходе к пониманию и анализу психологического знания осуществляется его систематическая психотехническая рефлексия, дополненная феноменологическим анализом. А это значит, что всякое психологическое знание осознается как знание практическое и технически ориентированное. Другими словами, вся и всякая психология понимается и рефлектируется и в психотехнической плоскости и таким образом превращается в практическую психологию. А это открывает огромные возможности развития прикладной и практической психологии.

\section{Список литературь:}

1. Адлер А. Наука жить. K.: Port-Royal, 1997.

2. Василюк Ф.Е. Методологический анализ в психологии. М.: МГППУ; Смысл, 2003.

3. Волошинов В.Н. (Бахтин М.М.) Марксизм и философия языка: Основные проблемы социологического метода в науке о языке. М.: Лабиринт, 1993.

4. Бахтин М.М. Эстетика словесного творчества. М., 1979.

5. Олешкевич В.И. История и логика развития европейской психотехники. М.: МОСУ, 2005.

6. Олешкевич В.И. Психология и психотерапия А. Адлера. М., 2010.

7. Олешкевич В.И. История психотехники. М.: Академия, 2002.

8. Розин В.М. Психологическая помощь. Психотехника. Эзотерический опыт: учеб. пособие. М.: Изд-во РОУ, 1995.

9. Розин В.М. Психология и культурное развитие человека: учеб. пособие. М.: Изд-во Российского открытого ун-та, 1994.

10. Фрейд 3. Введение в психоанализ: Лекции. М.: Наука, 1989.

11. Штайнер Р. Очерк теории Гетевского мировоззрения. М.: Парсифаль, 1993.

12. Юнг К.Г. Проблемы души нашего времени. М.: Прогресс-Универс, 1994.

13. Юнг К.Г. Тэвистокские лекции. Аналитическая психология: ее теория и практика. Киев: СИЕНТО, 1995.

\section{References (transliteration):}

1. Adler A. Nauka zhit. K.: Port-Royal, 1997.

2. Vasilyuk F.E. Metodologicheskiy analiz v psihologii. M.: MGPPU; Smysl, 2003.

3. Voloshinov V.N. (Bahtin M.M.) Marksizm i filosofiya yazyka: Osnovnye problemy sociologicheskogo metoda v nauke o yazyke. M.: Labirint, 1993.

4. Bahtin M.M. Estetika slovesnogo tvorchestva. M., 1979.

5. Oleshkevich V.I. Istoriya i logika razvitiya evropeyskoy psihotehniki. M.: MOSU, 2005.

6. Oleshkevich V.I. Psiholologiya i psihoterapiya A. Adlera. M., 2010.

7. Oleshkevich V.I. Istoriya psihotehniki. M.: Akademiya, 2002.

8. Rozin V.M. Psihologicheskaya pomosch. Psihotehnika. Ezotericheskiy opyt: Uchebnoe posobie. M.: Izd-vo ROU, 1995.

9. Rozin V.M. Psihologiya i kul'turnoe razvitie cheloveka: Uchebnoe posobie. M.: Izd-vo Rossiyskogo otkrytogo un-ta, 1994.

10. Freyd Z. Vvedenie v psihoanaliz: Lekcii. M.: Nauka, 1989.

11. Shtayner R. Ocherk teorii Getevskogo mirovozzreniya. M.: Parsifal', 1993.

12. Yung K.G. Problemy dushi nashego vremeni. M.: Progress-Univers, 1994.

13. Yung K.G. Tevistokskie lekcii. Analiticheskaya psihologiya: ee teoriya i praktika. Kiev: SIENTO, 1995. 